\title{
Prescriptive language attitudes in a dual language elementary school
}

\author{
Mary Hudgens Henderson*
}

\begin{abstract}
Language misconceptions are still very prevalent among the public, partially due to lack of linguistic education in schools. Language misconceptions can influence language attitudes, including the language attitudes of language-minority children towards their native language. In this study, 5th graders enrolled in a Dual Language program participated in an 18lesson language awareness curriculum and completed Likert-type pre/posttest surveys and pretest/posttest interviews. Students' prescriptive language attitude results are compared to those of an English-instruction control group that did not receive language awareness lessons. Both bilingual and monolingual students believed formal, school-based language to be superior to informal language. Despite their language awareness instruction, students in the treatment group continued to hold prescriptivist language attitudes. Implications for future language awareness curricula are discussed.
\end{abstract}

Keywords. language awareness; language attitudes; bilingual education; prescriptivism

1. Introduction. Since William Labov (1963) published his research on a sociallymotivated sound change on Martha's Vineyard, linguists have come to accept language variation as a natural and positive fact of human language. However, many people view language variation, and nonstandardized language varieties in particular, negatively. Misconceptions about language remain so extensive that an entire sub-field of sociolinguistics, Perceptual Dialectology, has developed around the study of what nonlinguists think about languages and dialects (e.g., Niedzielski \& Preston 1999).

The prevalence of language myths and misconceptions can be traced to the general lack of linguistic training among the public. The scientific study of language variation is absent in most K-12 curricula, and only a small fraction of teachers complete an introduction to linguistics course before they graduate. There is a long tradition of excluding language variation from formal studies; nonstandardized varieties are either studied as examples to avoid, or used as ways to represent literary characters (Wolfram 1998: 169).

Language misconceptions are particularly harmful to students learning English as a second language in the United States. Like their vernacular-speaking peers, English Language Learners (hereafter ELLs) are at risk of being misdiagnosed as learning disabled. This misdiagnosis stems in part from assessments in which the language variety of the school is presented as superior in form and function (Laffey, Pearce \& Steed 2014). Negative views towards the languages and language varieties of ELLs have measurable consequences, such as high drop out rates (Sheng, Sheng \& Anderson 2011), L1 attrition (Wong Fillmore 1991, 2000), and over-representation in special education (MacSwan \& Rolstad 2006). Language myths and misconceptions have a significant role in perpetuating lack of equal educational opportunity.

\footnotetext{
* Mary Hudgens Henderson, Winona State University (hudgenshenderson@winona.edu).
} 
This research project aims to combat harmful language misconceptions by developing a sociolinguistic outreach curriculum for bilingual public school students that promotes a positive view towards language variation. This study investigated the effectiveness of a language awareness curriculum for Spanish-English bilingual $5^{\text {th }}$ graders in improving language attitudes of $5^{\text {th }}$ graders.

2. Language attitudes of children. Children acquire and internalize language misconceptions, which can lead to negative attitudes towards certain languages or language varieties. Language attitudes have been found to impact language maintenance and language learning. Studies have found language anxiety among less proficient heritage language speakers (Tallon 2009), and these negative feelings can impact language fluency (Jee 2015). Grosjean (1982: 126) noted that negative attitudes towards the heritage language could lead to language shift in the bilingual population.

Furthermore, language attitudes often change as a bilingual child gets older. Tse (1998) found that childhood and adolescence is when many Asian American students go through a stage of ethnic identity development characterized by ambivalence towards or evasion of the native culture. This type of ethnic identity ambivalence has strong implications for maintenance of the heritage language, since negative attitudes towards the native culture can extend to the heritage language. In fact, studies have found that younger children tend to have positive attitudes towards their native or heritage language (Cho, Shin \& Krashen 2004, Shin \& Lee 2003), but as language-minority children progress through the elementary grades they may acquire an antipathy towards their native or heritage language (Oller \& Eilers 2002), and many begin to prefer the majority language (Portes \& Hao 1998). Lambert, Frankel and Tucker (1966) found that among French-Canadian girls aged 9-18 years old, preference for the dominant language (English) appears around age 12.

This development of language preference over time is important to consider in the context of bilingual education. Although many students in K-5 Dual Language programs receive instruction in both languages, the dominance of English in the school and the wider U.S. society is most certainly noticed by native Spanish-speaking students, since they are expected to transition to all-English middle and high schools. This school transition occurs at precisely the life stage that corresponds to Phinney's (1993) Ethnic Identity Search, that is, when an individual seeks to understand the relationship of ethnicity to identity. The end of Spanish language instruction could influence students' attitudes towards their native and second languages; students may perceive that society values English over Spanish in academics, for example.

3. Previous sociolinguistic outreach efforts. In recent years, language awareness instruction has been advanced in K-12 education to improve language attitudes (Rickford \& Rickford 1995, Wolfram, Adger, \& Christian 1999). Previous studies (e.g., Reaser 2006, Sweetland 2006) have shown the effectiveness of linguistically-informed curricula on the linguistic knowledge and language attitudes of K-12 students.

Current language awareness programs use contrastive analysis techniques in teaching Standard English. For example, the state of New York recommends contrastive analysis for Caribbean English Creole speakers. Students who speak Creole receive specialized instructional attention that is similar to English as a Second Language 
approaches and techniques. The state encourages educators to recognize that unfamiliarity with Standard American English does not constitute a language deficit or language disorder; only students who do not demonstrate proficiency in oral speech habits of the home community are assessed for a possible language disorder (Ruiz, Latortue, \& Rosefort n.d.: 25).

Despite the division between bidialectal programs and second language programs, ELLs can benefit from instruction that links dialect diversity in their first language to dialect diversity in their second language. In fact, this may help dispel the commonality myth, which assumes that a dialect-neutral version of the second language exists (Wolfram 1997). However, the language awareness approach has yet to be implemented with ELLs. Language-minority students often face a double challenge from language ideologies that devalue their native language over English, and devalue their native language variety (e.g., Spanglish) over a standard language variety. As a continuance of efforts to bridge linguistics and education (e.g., Charity Hudley \& Mallinson 2011, Denham \& Lobeck 2005, 2010, Reaser 2006, Sweetland 2006, West Brown 2009, Wheeler \& Swords 2006), this study constitutes a sociolinguistic outreach effort to the public school system, with a particular focus on students in a bilingual program. The following research question guided the design and analysis of the study:

After participating in a Sociolinguistic Awareness curriculum, do $5^{\text {th }}$ grade bilingual students demonstrate a change in Language Attitudes? If so, do students demonstrate long-term (5 calendar months) maintenance of change in Language Attitudes?

4. Method. Chester Nez Elementary School (a pseudonym), the school in the southwest United States where this study was conducted, has a student population that is lowincome (93\%), academically low-performing, with a large proportion of ELL students (40\%), and majority Hispanic (84.6\%). In 2012-2013, the school year prior to data collection, $20 \%$ of ELLs were proficient or advanced in Reading, and $20 \%$ of ELLs were proficient or advanced in Math.

Two fifth-grade intact classrooms were volunteered by their teachers to serve as potential participants. One class was taught in the Dual Language strand of the school (academic content in English and Spanish), and this class served as the Treatment group that received Sociolinguistic Awareness lessons taught by the researcher described below $(\mathrm{N}=24)$. The second class was taught academic content in English only, and served as the Control group by not receiving any additional sociolinguistic-based lessons $(\mathrm{N}=16)$.

As part of a larger study (Hudgens Henderson, 2016), a language awareness curriculum called the Language Variation and Style-Shifting for Fifth Graders (hereafter LVSS) was designed. The content selection and sequence of the LVSS curriculum was guided by previous language awareness research in addition to current Common Core State Standards in $5^{\text {th }}$ grade Language Arts. Language awareness curricula typically contain three components: (1) a tolerance component that builds respect for different language varieties; (2) a sociolinguistic component that explains language variation and core sociolinguistic concepts; and (3) a contrastive analysis component that gives students explicit compare/contrast practice between home and school language varieties (Charity Hudley \& Mallinson 2011, Wolfram 1998, Wolfram, Adger, \& Christian 1999). 
The LVSS curriculum interwove the three components throughout eighteen lessons, which were divided into four weeks of instruction. The first week addressed specific sociolinguistic concepts, such as the definitions of terms language and dialect. The second week addressed language discrimination, making participants aware of language bias as well as the concept of linguistic equality. The third week stressed the importance of style-shifting, or the need for speakers to match their language according to audience, context, and task. The fourth week was dedicated to explicitly comparing and contrasting standard dialects and other language varieties, practice style-shifting to an academic variety of language, and a reflection on what participants learned about language variation and style-shifting.

The study followed a quasi-experimental longitudinal design in which both groups completed pretest and posttest surveys and interviews. Data sources from Treatment and Control groups include: a) numerical results from a 20-item Likert-type survey that served as the pretest, immediate posttest, and two delayed posttests; and b) qualitative conversational interviews from six randomly selected participants from each group conducted before and after the Sociolinguistic Awareness lessons. The following discussion focuses on a subset of the language survey that assessed prescriptive language attitudes.

Three survey items measured student attitudes of prescriptive norms: Item 1, EVERYONE SHOULD SPEAK A LANGUAGE THE SAME WAY ALL THE TIME; Item 12, THE LANGUAGE WE LEARN IN SCHOOL IS THE CORRECT KIND OF LANGUAGE; and Item 19, FORMAL LANGUAGE IS ALWAYS BETTER THAN INFORMAL LANGUAGE. It was hypothesized that after lessons in linguistic equality and dialect patterning, students would disagree with the prescriptivist positions these statements take.

5. Results. Studies have found that young children tend to think of language errors in terms of comprehensibility/intelligibility, or in terms of what the children are used to hearing (Millar 2003). That is, young children may not necessarily have a standard language variety in mind when they judge grammaticality, but instead consider the local language variety that they are exposed to as the standard against which to judge other varieties. Therefore, a pressing question is at what age or development stage do children begin to believe the standard language variety as the "correct" variety? As the discussion below shows, these ten-year-old students already had notions that decent, proper language was taught in school.

Students participating in the LVSS lessons were introduced to the idea of formal vs. informal language by the fifth lesson, in which students compared generational uses of slang terms in English. The third week of lessons constituted the bulk of the instruction on formal and informal language distinctions, in the context of style-shifting.

In the tenth lesson, I asked the students to define what formal and informal meant. For formal, students volunteered the words elegant, fancy, and decent to explain this term. For informal, students volunteered the words casual, normal, and not proper. Taking into consideration the students' association of formal with "decent" and informal with "not proper", we discussed the word "wassup" (what's up?), which is considered informal but still appropriate to certain situations. I attempted to dispel the notion that formal meant "correct" and informal meant "incorrect" (field notes, December 5, 2013). 
The eleventh lesson began with a discussion on how the use of formal or informal language can influence a person's perception of a character. To illustrate this phenomenon, short selections were read aloud from two popular children's series, Diary of a Wimpy Kid (book one) by Jeff Kinney, and A Series of Unfortunate Events (book one) by Lemony Snicket. Kinney's books are written in an informal style that mimics an adolescent male's diary, while Snicket writes in a formal style charaterized by large words, complex syntax, and intellectual topics. Kinney's protagonist, Greg, is an American middle-schooler who discusses his daily struggles with annoying siblings, bullies, and awkward social situations. Snicket's protagonists are the reverse of Gregthe Baudelaire orphans are children of rich parents, they lived in a mansion, and they are academically gifted. Greg's story is set in present-day United States, while the Baudelaire's story is set in an anachronistic place similar to $19^{\text {th }}$ century Britain. As a result of these and other differences, the narration and dialogue of the two book series stand in stark contrast in terms of lexical content and grammatical style.

After listening to the "Cheese Touch" section of Kinney's book (pp. 8-10), and "the death of the parents" section in Snicket's book (pp. 6-10), we discussed the formality/informality of the writing style and how it affected our perceptions of the protagonists. The students agreed that Greg appeared casual, and the Baudelaire orphans appeared fancy. We discussed how the writing style was appropriate for the charactersGreg tried very hard to appear normal, while the Baudelaire orphans seemed to stand out (field notes, December 5, 2013).

5.1. ITEM 19, FORMAL LANGUAGE IS ALWAYS BETTER THAN INFORMAL LANGUAGE. The Response Index reported for each item below represents the percentage of students who responded with positive language attitudes (i.e., disagreeing with prescriptivist statements or agreeing with descriptivist statements). Considering the extent to which the lessons went in discussing how formality was contrasted with informality in terms of appropriateness, the results for Item 19, FORMAL LANGUAGE IS ALWAYS BETTER THAN INFORMAL LANGUAGE, were surprising. Over a third of the Treatment students disagreed with this statement on the Pretest $(42 \%, \mathrm{~N}=10)$, but fewer students disagreed on Posttest1 $(30 \%, N=7)$, Posttest $2(24 \%, N=5)$, and Posttest $3(33 \%, N=7)$. An unexpected trend is the rise in number of Treatment students who agreed with this item on Posttestl (fifteen students, versus ten students on the Pretest). It is clear that many students continued to believe that formal language was more "correct" than informal language.

Meanwhile the opposite trend occurred in the Control group, with more Control students disagreeing on Posttest 1 (Figure 1 below). The Control group students actually showed more disagreement with this item from the Pretest $(23 \%, \mathrm{~N}=3)$ to Posttest1 $(47 \%, N=7)$. However, this surge in disagreement was not sustained on Posttest $2(8 \%, N$ $=1)$ or Posttest $3(17 \%, N=2)$. The Control group also showed a high proportion of students expressing uncertainty at all four survey time-points, ranging from between $62 \%$ on the Pretest to $33 \%$ on Posttest 1 . 


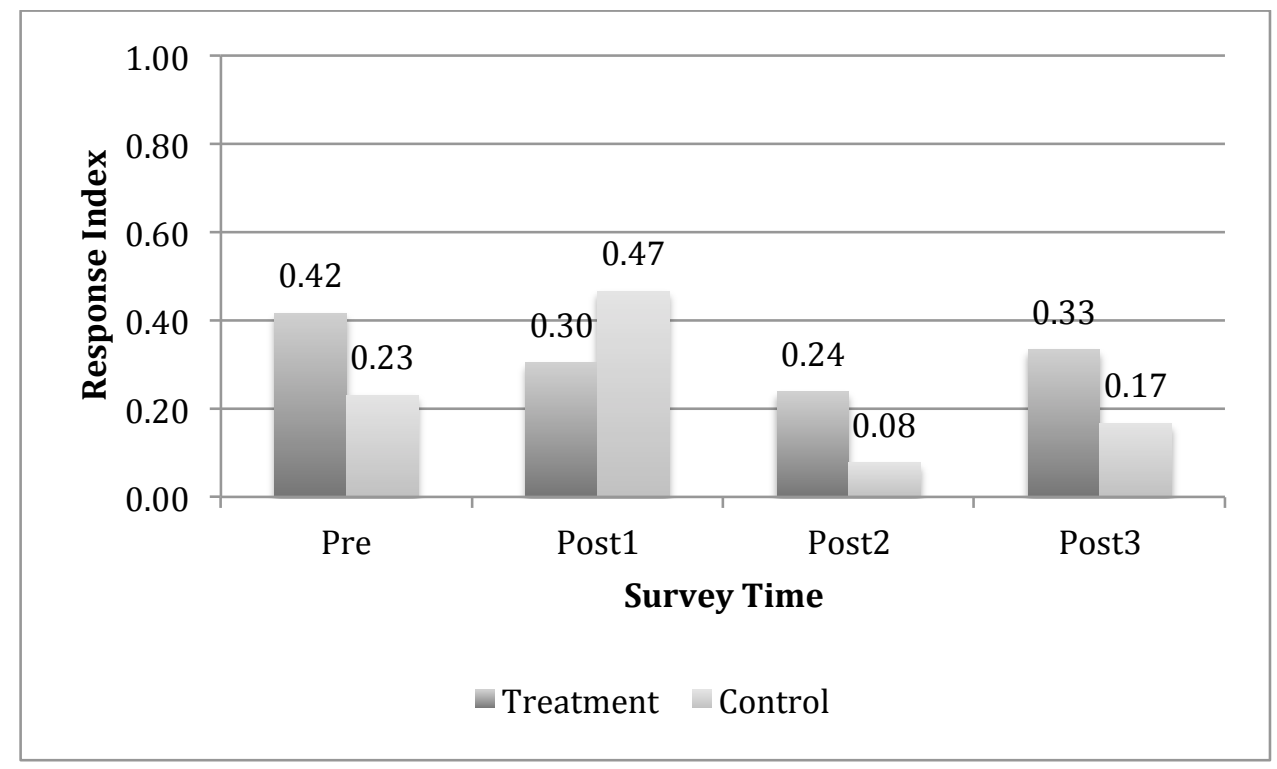

Treatment: $\chi^{2}(3, \mathrm{~N}=17)=2.297, \mathrm{p}=0.513$

Control: $\chi^{2}(3, \mathrm{~N}=9)=3.346, \mathrm{p}=0.341$

Figure 1: Response index for Item 19, FORMAL LANGUAGE IS ALWAYS BETTER THAN INFORMAL LANGUAGE

The interviews confirm that Treatment students resisted the view that informal language could be more appropriate to certain contexts than formal language. On Posttest1, four of the six interviewed Treatment students (Daniela, Emmanuel, Mariana, and Sofia) believed formal language to be better than informal language. Although Emmanuel and Sofia acknowledged the need for style-shifting, they still insisted that formal language was better. Emmanuel conceded that "like when you're with your friends you could talk informal", but aligned more with Sofia's view: "el lenguaje formal es más decente que el informal ${ }^{\dagger}$ ". On her part, Mariana insisted that people do not like being spoken to in a casual manner. For these students, formal language was more decent and respectable than informal language.

Only two interviewed Treatment students, David and Matias, believed that formal language was not always better than informal language. In his explanation, Matias showed understanding that style-shifting requires a speaker to switch between formal and informal types of language. He gave the example of "una fiesta de teenagers" where speaking formally "no sería como normal"; ; speaking informally would be expected.

It is evident that many Treatment students were not convinced that one language variety is not inherently superior to another. Some students may have interpreted this item to mean "formal language is more appropriate/proper than informal language" (although that should also attract disagreement responses); the term "better" is potentially ambiguous in this context. A more specific wording of this item such as "Formal

$\dagger$ "formal language is more decent than informal language"

$\$$ "a teenagers' party"

$\S$ "would not be, like, normal" 
language is always more correct/suitable than informal language" could have avoided possible misinterpretation.

Two of the six interviewed Control students believed formal language to be superior to informal language. Zack explained: "formal language is better, always better" and Billy explained "it's probably more appropriate" to use formal language. In contrast, Liz took a more laissez-faire approach: "like you can speak formal language if you want to or you can speak informal language if you want to." It was unclear if Liz was aware of context-constrained uses of language.

Interestingly, Sonya, the only bilingual student in the English-instruction Control group, believed Spanish to be "formal" and English to be "informal". She explained that this was related to the language dominance at home: "because I don't, I don't speak too much English at the house, talk a lot of Spanish because my parents don't talk English." It appears that her use of English with friends and Spanish with family is the main distinction between formal and informal language.

In sum, it appears that the overt prestige of formal speech swayed many Treatment and Control students into believing it was always better. Although some students admitted that informal speech was necessary for informal situations, it seems that the low social status of informal speech keeps it from being perceived as more appropriate than formal language, regardless of the context. The high level of agreement with this item shows the strength that prescriptivist attitudes hold even among pre-adolescent children.

\subsection{ITEM 12, THE LANGUAGE WE LEARN IN SCHOOL IS THE CORRECT KIND OF LANGUAGE.}

The next survey item confirmed that socially prestigious language influences student views of language correctness. Item 12, THE LANGUAGE WE LEARN IN SCHOOL IS THE CORRECT KIND OF LANGUAGE, showed very humble growth on the Treatment group's Posttest1 scores, before descending to negligible disagreement levels (Figure 2 below). While the Treatment group's scores increased four points from 17\% (Pretest, $\mathrm{N}=4$ ) to $21 \%$ (Posttest $1, \mathrm{~N}=5)$, the disagreement levels tumbled to $10 \%$ (Posttest2, $\mathrm{N}=2$ ) and $4 \%$ (Posttest3, $\mathrm{N}=1$ ), resulting in the weakest results of the entire survey. There is no clear pattern that emerges from the Treatment students who disagreed with this item. The only student who disagreed with this item on Posttest3, Diego, had agreed with this item on all three earlier surveys. One student, Jeronimo, changed his answers on each survey: he disagreed on the Pretest and Posttest2, but agreed on Posttest1 and Posttest3. Another student, Valentina, disagreed on the Pretest and Posttest1, but changed her mind by Posttest 2 and Posttest3. Most Treatment students agreed or strongly agreed with this item, with agreement remaining somewhat steady over time. However, by the end of the school year, more Treatment students expressed doubt (six students) on this item. Perhaps the increased doubt indicates that more students are questioning whether school-based language is the only correct kind of language.

Meanwhile, the Control group maintained scores from Pretest $(31 \%, N=4)$ to Posttest1 $(33 \%, \mathrm{~N}=5)$, before also experiencing a fall in disagreement levels on Posttest2 $(8 \%, \mathrm{~N}=1)$. Three Control students $(21 \%)$ disagreed on Posttest3. 


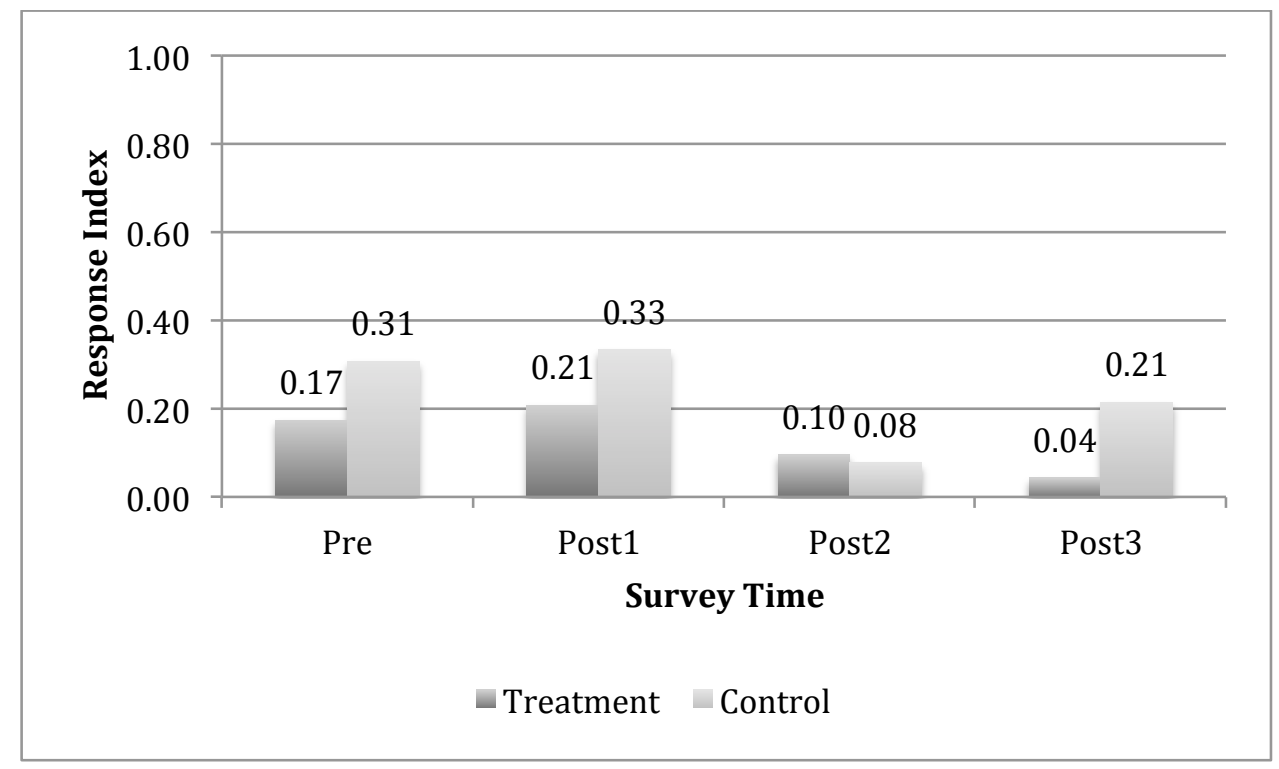

Treatment: $\chi^{2}(3, N=19)=6.124, p=0.106$

Control: $\chi^{2}(3, N=10)=2.937, p=0.401$

Figure 2: Response index for Item 12, THE LANGUAGE WE LEARN IN SCHOOL IS THE CORRECT KIND OF LANGUAGE

The interviews showed that many students in both groups interpreted the phrase "the language we learn in school" to mean learning English in school, as opposed to the type of English or the type of Spanish one learns in school. Thus, this survey item may be a more accurate indicator of how students view the status of English or Spanish in the schools. In her Pretest interview, Treatment student Sofia explained that English is the correct language to use in school, but Spanish is also acceptable. In her Posttest1 interview, Sofia reiterated that English was the correct language because it was taught in schools and it is the main language of the U.S. She then went on to explain that the language taught in school was superior to the language heard in the streets, because it was more "decent":

Sofía: Puse que sí estoy de acuerdo porque pienso que es el lenguaje que tenemos que aprender aquí.

Mary: ¿Y es correcto?

Sofía: Sí.

Mary: ¿Es mejor que otro tipo de lenguaje? Por ejemplo ¿el tipo de lenguaje que se oye en la calle, o el campo de recreo?

Sofia: Es mejor que el lenguaje de la calle o de otro lugar.

Mary: ¿Por qué? 
Sofía: Porque aquí es más decente y en otros lugares no tanto.*

Thus, even in Sofía's understanding of the dominance of English in the U.S., she still believed school-based language was superior to language found in other less formal locations.

Despite this English/Spanish dichotomous interpretation of some students, Emmanuel and Matias caught the intended meaning of formal versus informal language. Explaining his agreement, Emmanuel said that speaking formal is a valuable skill for a child to learn, and went on to explain how his father corrects his use of Spanglish:

Mary: So do you think that the school language is um, uh is the only correct kind of language, or there's others?

Emmanuel: There's others.

Mary: Like what?

Emmanuel: Like um the one, like at the house.

Mary: So why is that correct also?

Emmanuel: Because um my dad he's um, like say something wrong, he always, he always like corrects me.

Mary: Oh yeah? Can you give me an example?

Emmanuel: Like um when I say parqueando [parking], he tells me that it's estacionar [parking], like that.

Emmanuel's example shows that children are exposed to prescriptivist ideologies at home as well as school. In his case, Emmanuel speaks "correct" Spanish at home due to his father's vigilance. Here, the Standard Spanish estacionar is preferred over the Spanglish verb parquear.

Five out of six interviewed Control group students also interpreted this item to mean English is the correct language to be taught in schools (it was unclear if Liz, the sixth student, interpreted it this way as well). Three of those students (Billy, Zack, and Henry) agreed with the statement, explaining that English was the proper language for the United States. Billy qualified his English-only ideology with a tolerance of diversity: "but you can, they, they'll accept like any kind of person from somewhere else." This interpretation of the survey item points to how elementary students are indoctrinated in English-only policies in schools; English is seen to be the "correct" language and learning any other language is marked. Previous research has pointed out the discriminatory practices of conducting multicultural education in English and in standard language varieties (e.g., Macedo 1991; Macedo \& Bartolomé 2014). It is clear that students as young as ten years old are convinced of the natural predominance of English over all other languages in the United States.

\footnotetext{
${ }^{* *}$ Sofia: I put yes I agree because I think it is the language we have to learn here. Mary: And it is correct?

Sofia: Yes.

Mary: It is better than another type of language? For example, the type of language that is heard in the street, or in the playground?

Sofia: It's better than the language of the street or of other places.

Mary: Why?

Sofia: Because here it is more decent and in other places not so much.
} 
Sonya, the bilingual student, was the only interviewed Control group student to disagree with this item. She also interpreted it to mean English is the correct language to be taught in schools. In her Pretest interview, she directly confronted the monolingual English ideology circulating among her peers: "Some kids could talk Spanish in school also, they just don't have to talk English too." Although she was in an English-medium classroom, Sonya defended the right to use Spanish at school. Sonya's resolve on this issue wavered as the school year went on; she marked Don't Know on Posttest1 and Posttest2, but marked Strongly Disagree on Posttest3.

In sum, the misinterpretation of the item points to the English-only ideology, or at least English-preferred ideology, that is prevalent even in schools with Dual Language programs. That is, it is apparent that educators must critically examine the use of the English language, which exerts a hegemonic presence even in programs committed to bilingualism. This item could benefit from a clarification of the phrase "the language we learn in school" to emphasize varieties of a language, as opposed to the actual language spoken in school (English or Spanish). Despite the ambiguity, it is clear that the majority of students believed school-based language varieties to be superior and even necessary for their academic futures. The next item probed how prescriptivist ideologies influenced a participant's view of style-shifting.

5.3. ITEM 1, EVERYONE SHOULD SPEAK A LANGUAGE THE SAME WAY ALL THE TIME. The third survey item related to prescriptivist attitudes showed high levels of tolerant attitudes in both groups. This is unexpected given the prescriptivist tendencies illustrated in the previous two survey items. The Treatment group's scores increased four points from $79 \%$ (Pretest, $\mathrm{N}=19$ ) to $83 \%$ (Posttest1, $\mathrm{N}=20$ ), before decreasing to $71 \%$ (Posttest2, $\mathrm{N}=$ 15 ) and increasing again to $82 \%$ (Posttest $3, \mathrm{~N}=18$ ) (Figure 3 below). This mild rollercoaster trajectory shows that in general Treatment students disagreed that everyone must speak a language the same way. Although scores stayed relatively steady from Pretest to Posttest1, there is an increasing strength in disagreement by Posttest3, with twelve students strongly disagreeing. Along with low levels of Don't Know responses, the increase in Strongly Disagree responses indicates that students felt more certain about their responses. The Control group students scored similarly to their Treatment group peers $(77 \%$ on the Pretest, $\mathrm{N}=10)$, except on Posttest 3 when all fourteen responding students disagreed with this item, a rare show of unanimity. 


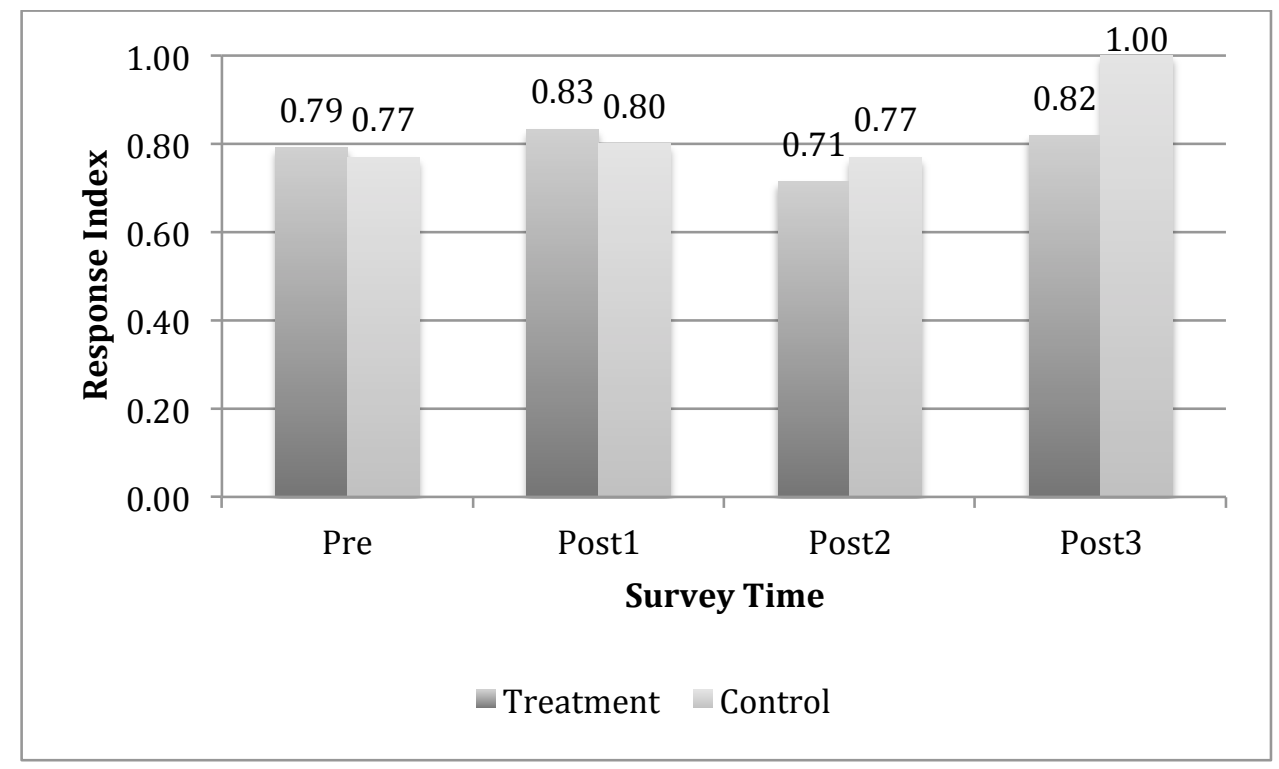

Treatment: $\chi^{2}(3, \mathrm{~N}=19)=2.95, \mathrm{p}=0.399$

Control: $\chi^{2}(3, \mathrm{~N}=10)=3.926, \mathrm{p}=0.27$

Figure 3: Response index for Item 1, EVERYONE SHOULD SPEAK A LANGUAGE THE SAME WAY ALL THE TIME

In the pretest interviews, all six Treatment students disagreed with this item because it conflicted with their notions of fairness and social justice. Several Treatment students interpreted this to mean that people should speak one language over another, instead of the intended meaning of speaking one language variety over another. For example, Emmanuel explained: "cause um, everyone should talk their own language that they speak, um, all the time, if they want". David initially understood the phrase speaking the same way all the time to mean two people talking simultaneously who cannot hear each other. I clarified the meaning for him by asking if someone should change their way of talking if everyone at school spoke differently. David responded no, "porque así es como habla ${ }^{\dagger \dagger "}$ but he went on to suggest that the person should try to be understood.

In his Posttest1 interview, Emmanuel mentioned conforming to conventions of an academic topic:

Emmanuel: Like sometimes [people should speak a language the same way] when you're like doing like math and um, you say um, you like say like "equation" and those words, and they say it the same sometimes.

Mary: So no matter what you're doing in math you have to use the same like math words?

Emmanuel: Yeah.

Emmanuel points out that students are required to use the same academic language for certain topics at school, and therefore they do have to "speak the same way all the time".

$\Uparrow$ "Because that's just the way they talk." 
In their interviews, all six Control group students also expressed the idea that people can speak a language other than English if they want, reflecting both the social fairness ideals like their Treatment group peers, and many interpreted this item to mean between-languages variation, instead of the intended within-languages variation. The attitudes expressed for this item contrast starkly with the attitudes expressed for the two previous prescriptivist attitudes survey items, in which many students expressed the opinion that English was the "correct" language and that formal language was superior to informal language. It is clear that this item, unlike the other two, stimulated the students' sense of social justice and fairness. It is interesting that many students did not see the dominance of English in school and society as a social justice issue; apparently the use of English over other languages in academics is not perceived as an equal rights issue. While many students believed "you should be able to speak your language if you want" (Billy), in practice English was the preferred language, at least among the monolingual students.

Once again, Sonya, the bilingual Control student, offered a perspective on this issue that was not evident among the monolingual Control students. She explained her disagreement with this item, stating: "because I could talk English here and they can't do anything if I speak Spanish here too.” Sonya's choice of words is telling. Even in a school with a Dual Language strand, bilingual students must be protective of their right to use Spanish, a language that is obviously disfavored among monolingual peers and in mainstream society in general. Thus, despite the outward projection of tolerance, Spanish is still under threat even in schools with bilingual programs.

In sum, many Treatment and Control students disagreed with this item because it triggered their notions of fairness and social justice. Although the Treatment group's scores appears to show little change across the four survey time-points, the strength of disagreement increased over time, with 12 out of 23 students choosing Strongly Disagree on Posttest3, compared with only 6 students on the Pretest. Nevertheless, the wording of the item must be clarified so that students understand a within-language comparison instead of a between-languages comparison.

To summarize the three prescriptive language attitudes items, the Sociolinguistic Awareness lessons did not appear to impact significantly the Treatment students' attitudes towards what was perceived as the "correct" language. On Posttest1, more Treatment students believed formal language to always be better than informal language, and the majority agreed that school-based language was "the correct kind of language". However, approximately three-fourths of the Treatment class rejected the statement that "everyone should speak a language the same way all the time", indicating that despite the overwhelming preference for formal, school-based language, students are aware that language variation does and should exist. It is evident that beliefs in fairness and justice do not preclude preferring one language variety over another. Furthermore, the hegemonic position of English, and Standard English, remained unquestioned for many students. Future Sociolinguistic Awareness curricula may consider further steps in problematizing the overarching preference for English that hides behind a veil of tolerance for multilingualism, especially in bilingual programs.

6. Conclusion. The majority of Treatment students continued to hold prescriptive language attitudes after participating in the lessons, and by the end of the school year 
prescriptive ideologies appeared to be still firmly entrenched. This study indicates that bilingual students have similar prescriptive language attitudes as monolingual students. Despite heightened meta-linguistic awareness, bilingual students are still susceptible to language myths and misconceptions, especially regarding the perceived "correctness" of certain dialects and perceived "normality" of speaking.

Linguists have a moral imperative to counter language myths, misconceptions and ideologies, following Labov's (1982) principle of error correction and principle of debt incurred. Labov argued that according to the principle of error correction,

A scientist who becomes aware of a widespread idea or social practice with important consequences that is invalidated by his own data is obligated to bring this error to the attention of the widest possible audience. (Labov 1982: 172)

That is, scientists have a moral obligation to attempt to alter misconceptions that they know to be untrue. In this case, it is untrue that English is superior to Spanish, and it is untrue that nonstandardized varieties of Spanish (such as Spanglish) are inferior to a standardized Spanish. Incorporating the scientific study of language variation into K-12 educational curriculum is an important first step in dismantling language myths and misconceptions among teachers, parents and children; it is also a way for linguists to "pay back" the communities from which linguists extract data (Labov 1982, Wolfram 1993). Understanding the systemic and patterned nature of the language of human beings should be a vital component in achieving a deeper understanding of diversity.

Native Spanish-speaking students in the United States deserve the special attention of linguists and educators who are dedicated to improving language awareness in schools. As the largest linguistic minority in the United States, Spanish-speakers are in a position to leverage recognition of their linguistic and cultural needs. Spanish-speaking students in the United States not only have need of bilingual education programs, but also linguistically-sensitive curricula that take into account their particular varieties of Spanish.

Nevertheless, more must be done to get young people to question established notions of correct versus incorrect language. The few lessons taught in the LVSS curriculum were evidently not successful in dislodging prescriptivist ideologies; young people may need more contact with positively-framed language study before they begin to connect the dots with how prescriptivism is related to language prejudice.

\section{References}

Charity Hudley, A. H., \& Mallinson, C. 2011. Understanding English language variation in U.S. schools. New York: Teachers College Press.

Cho, G., Shin, F., \& Krashen, S. 2004. What do we know about Heritage Languages? What do we need to know about them? Multicultural Education, 11(4), 23-26.

Denham, K. E., \& Lobeck, A. C. 2005. Language in the schools: Integrating linguistic knowledge into K-12 teaching. Mahwah, N.J.: L. Erlbaum Associates.

Denham, K. E., \& Lobeck, A. C. 2010. Linguistics at school: Language awareness in primary and secondary education. Cambridge, UK: Cambridge University Press. 
Grosjean, F. 1982. Life with two languages: An introduction to bilingualism. Cambridge, Mass.: Harvard University Press.

Hudgens Henderson, M. 2016. Sociolinguistics for kids: A curriculum for bilingual students. Albuquerque, NM: University of New Mexico dissertation.

Jee, M. J. 2015. Exploring Korean heritage language learners' anxiety: 'We are not afraid of Korean!'. Journal Of Multilingual And Multicultural Development, (2015 04 20). http://dx.doi.org/10.1080/01434632.2015.1029933.

Labov, W. 1963. The social motivation of a sound change. WORD: Journal of the International Linguistic Association, 19, 273-309.

Labov, W. 1982. Objectivity and commitment in linguistic science: The case of the Black English trial in Ann Arbor. Language In Society, 11(2), 165-201. DOI:10.2307_4167310.

Laffey, K., Pearce, W. M., \& Steed, W. 2014. Effect of dialect on the identification of speech impairment in indigenous children. Australian Review Of Applied Linguistics, 37(2), 161-177.

Lambert, W.E., Frankel, H., \& Tucker, G.R. 1966. Judging personality through speech: a French-Canadian example. The Journal Of Communication, 16(4), 305-21.

Macedo, D. 1991. English only: The tongue-tying of America. The Journal of Education, 173(2), 9-20.

Macedo, D., \& Bartolomé, L. I. 2014. Multiculturalism permitted in English only. International Multilingual Research Journal, 8(1), 24-37. http://dx.doi.org/10.1080/19313152.2014.852426.

MacSwan, J., \& Rolstad, K. 2006. How language proficiency tests mislead us about ability: Implications for English Language Learner placement in special education. Teachers College Record, 108(11), 2304-2328.

Millar, S. 2003. Children and linguistic normativity. In D. Britain and J. Cheshire (Eds.), Social dialectology in honor of Peter Trudgill (pp. 287-297).

Amsterdam/Philadelphia: John Benjamins.

Niedzielski, N. A., \& Preston, D. R. 1999. Folk linguistics. Berlin; New York: Mouton de Gruyter.

Oller, D. K., \& Eilers, R. E. 2002. Language and literacy in bilingual children (Child language and child development, 2). Clevedon, England: Multilingual Matters.

Phinney, J. S. 1993. A three-stage model of ethnic identity development in adolescence. In M. E. Bernal \& G. P. Knight (Eds.), Ethnic identity: Formation and transmission among Hispanics and other minorities (pp. 61-79). New York: State University of New York Press.

Portes, A., \& Hao, L. 1998. E Pluribus Unum: Bilingualism and loss of language in the second generation. Sociology Of Education, 71(4), 269-94.

http://dx.doi.org/10.2307/2673171. 
Reaser, Jeffrey. 2006. The effect of dialect awareness on adolescent knowledge and attitudes. Durham, NC: Duke University dissertation.

Rickford, J. R., \& Rickford, A. 1995. Dialect readers revisited. Linguistics and Education, 7(2), 107-28.

Ruiz, P., Latortue, R., \& Rosefort, N. no date. Resource guide for the education of New York state students from Caribbean countries where English is the medium of instruction. New York State Education Department \& University of the State of New York. Albany, NY. New York State Haitian Language BETAC.

Sheng, Z., Sheng, Y., \& Anderson, C. J. 2011. Dropping out of school among ELL students: Implications to schools and teacher education. Clearing House: A Journal Of Educational Strategies, Issues And Ideas, 84(3), 98-103. http://dx.doi.org/10.1080/00098655.2010.538755.

Shin, F., \& Lee, B. 2003. Language shift co-occurs with positive attitudes toward the heritage language. Mosaic: A Journal For Language Teachers, 8(1), 7-9.

Sweetland, Julie. 2006. Teaching writing in the African American Classroom: A sociolinguistic approach. Stanford, CA: Stanford University dissertation.

Tallon, M. 2009. Foreign language anxiety and heritage students of Spanish: A quantitative study. Foreign Language Annals, 42(1), 112-137. http://dx.doi.org/10.1111/j.1944-9720.2009.01011.x.

Tse, L. 1998. Seeing themselves through borrowed eyes: Asian Americans in ethnic ambivalence/evasion. MultiCultural Review, 7(2), 28-34.

West Brown, D. 2009. In other words: Lessons on grammar, code-switching, and academic writing. Portsmouth, N.H.: Heinemann.

Wheeler, R., \& Swords, R. 2006. Code-switching: Teaching Standard English in urban classrooms. Urbana, IL: National Council of Teachers of English.

Wolfram, W. 1993. Ethical considerations in language awareness programs. Issues In Applied Linguistics, 4(2), 225-55.

Wolfram, W. 1997. The role of dialect differences in cross-cultural communication: Proactive dialect awareness. Bulletin Suisse de Linguistique Appliquée, 65, 143154.

Wolfram, W. 1998. Dialect awareness and the study of language. In A. Egan-Roberts \& D. Bloome (Eds.), Students as researchers of culture and language in their own communities (pp. 167-190). Cresskill, NJ: Hampton Press.

Wolfram, W., Adger, C., \& Christian, D. 1999. Dialects in schools and communities. Mahwah, NJ: Lawrence Erlbaum.

Wong Fillmore, L. 1991. When learning a second language means losing the first. Early Childhood Research Quarterly, 6(3), 323-47.

Wong Fillmore, L. 2000. Loss of family languages: Should educators be concerned?

Theory Into Practice, 39(4), 203-10.

http://dx.doi.org/10.1207/s15430421tip3904_3. 